\title{
Using Relative Weights To Reanalyze 'Settled' Areas Of Organizational Behavior Research: The Job Characteristics Model And Organizational Justice
}

Scott J. Behson, Fairleigh Dickinson University, USA

\begin{abstract}
There is a danger that, as areas of research become established, the conceptual underpinnings of key models are no longer critically analyzed. In this study, I use meta-analytic data from two such areas of organizational behavior research, the Job Characteristics Model and the Four-Factor Conception of Organizational Justice, as the basis of critical re-analysis. Specifically, I use a recently-developed analytic technique, relative weights (Johnson, 2001), to re-examine metaanalytic data from both research areas. In both cases, the results of the re-analysis run counter to some established predictions, indicating that these fields could benefit from further research and rethinking.
\end{abstract}

Keywords: Relative weights, meta-analysis, organizational justice, job design, Job Characteristics Model

\section{INTRODUCTION}

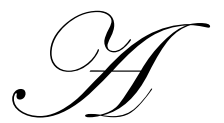

ccording to a framework developed by Reichers and Schneider (1990), a good deal of organizational behavior literature can be considered as being in the "consolidation and accommodation" stage of scientific inquiry, which occurs after stage 1- "introduction and elaboration", in which new models are proposed and tested, and stage 2- "evaluation and augmentation", in which models are subjected to scrutiny, tested against alternate models, and are expanded upon. In the "consolidation and accommodation" stage, there is a reduction in controversies and an agreement on definitions, antecedents and consequences. This is especially true of the Job Characteristic Model and other models of the motivational effects of job design, as well as research into organizational justice, which both began in earnest in the 1960s and 1970s. While this means that the basic tenets of job design and organizational justice have become established and codified into management practice, academic reviews and college textbooks, there is a danger that established areas of agreement are no longer questioned or critically reanalyzed. The goal of the present research is to critically reanalyze the research on the Job Characteristics Model and Organizational Justice using comprehensive metaanalytic data and a recently-developed statistical technique best suited towards this type of investigation. In this way, the continued validity of these important organizational behavior research areas can either be supported or called into question.

\section{Study 1- Job Characteristics Model}

Hackman and Oldham's $(1975,1976,1980)$ Job Characteristics Model (JCM) is one of the most influential theories ever presented in the field of organizational behavior. It has served as the basis for scores of studies and job redesign interventions over the past three decades, and this research has been extensively reviewed (Fried \& Ferris 1987; Loher, Noe, Moeller \& Fitzgerald, 1985; Taber \& Taylor, 1990). The majority of research has supported the overall validity of the JCM, although critiques and modifications have been offered (Roberts \& Glick, 1981; Salancik \& Pfeffer, 1978), and the role of the CPS has been questioned (Boonzair \& Ficker, 2001). 
Specifically, the JCM proposes that the satisfaction and intrinsic motivation an employee feels at work is directly related to their experience of three critical psychological states (CPS) (i.e., experienced meaningfulness, experienced responsibility, and knowledge of results). In turn, these CPS can be elicited by five core job characteristics (CJC) (i.e., skill variety, task identity, task significance, autonomy, and feedback from the job itself). It has often been described as a fully mediated model (Behson, Eddy \& Lorenzet, 2000). This model is pictured in Figure 1.

Interestingly, an evaluation of the research that has been conducted on the JCM suggests that few researchers have tested the model the way in which it was originally proposed. Most studies using the JCM framework have omitted the CPS, and have instead investigated only the direct relationships between the CJC and a number of outcomes. (Renn \& Vandenberg, 1995). This seems to have occurred despite no theoretical or practical rationale for this practice (Fried \& Ferris, 1987; Hogan \& Martel, 1987; Renn \& Vandenberg, 1995). This consistent omission of the CPS from empirical investigations of the JCM could lead to erroneous predictions (Fox \& Feldman, 1988).

Further, this lack of available data has prevented two of the three major meta-analytic reviews of the JCM from making definitive statements about the CPS. While Fried and Ferris (1987) included 76 studies in their metaanalysis of the JCM, they could find only eight studies that examined the entire JCM (i.e., including the CPS) and only three that tested the mediating effects of the CPS. Thus, Fried and Ferris (1987) were unable to make definitive conclusions as to the validity or importance of the CPS, although they stated in their qualitative discussion that there was suggestive evidence that the CPS are critical to the model. The Loher et al. (1985) meta-analysis did not address the critical psychological states at all. Rather, it focused solely on the relationships between the CJC and satisfaction. Behson, et al. (2000) conducted a meta-analysis including only studies that included all elements of the JCM and tested alternative models (i.e., the JCM with and without including the CPS) using their meta-analytic data as input to a structural equations modeling analysis. They found evidence that the full JCM model explained more variance in the dependent variables and contained a greater percentage of statistically significant causal pathways than the abridged version of the JCM, but that the full model represented a poorer fit to the data. This supported the importance of utilizing the full JCM over partial models.

Figure 1

Hackman \& Oldham's (1976) originally-conceived Job Characteristics Model with the meta-analytic and structural equation modeling results from Behson, Eddy \& Lorenzet (2000) included

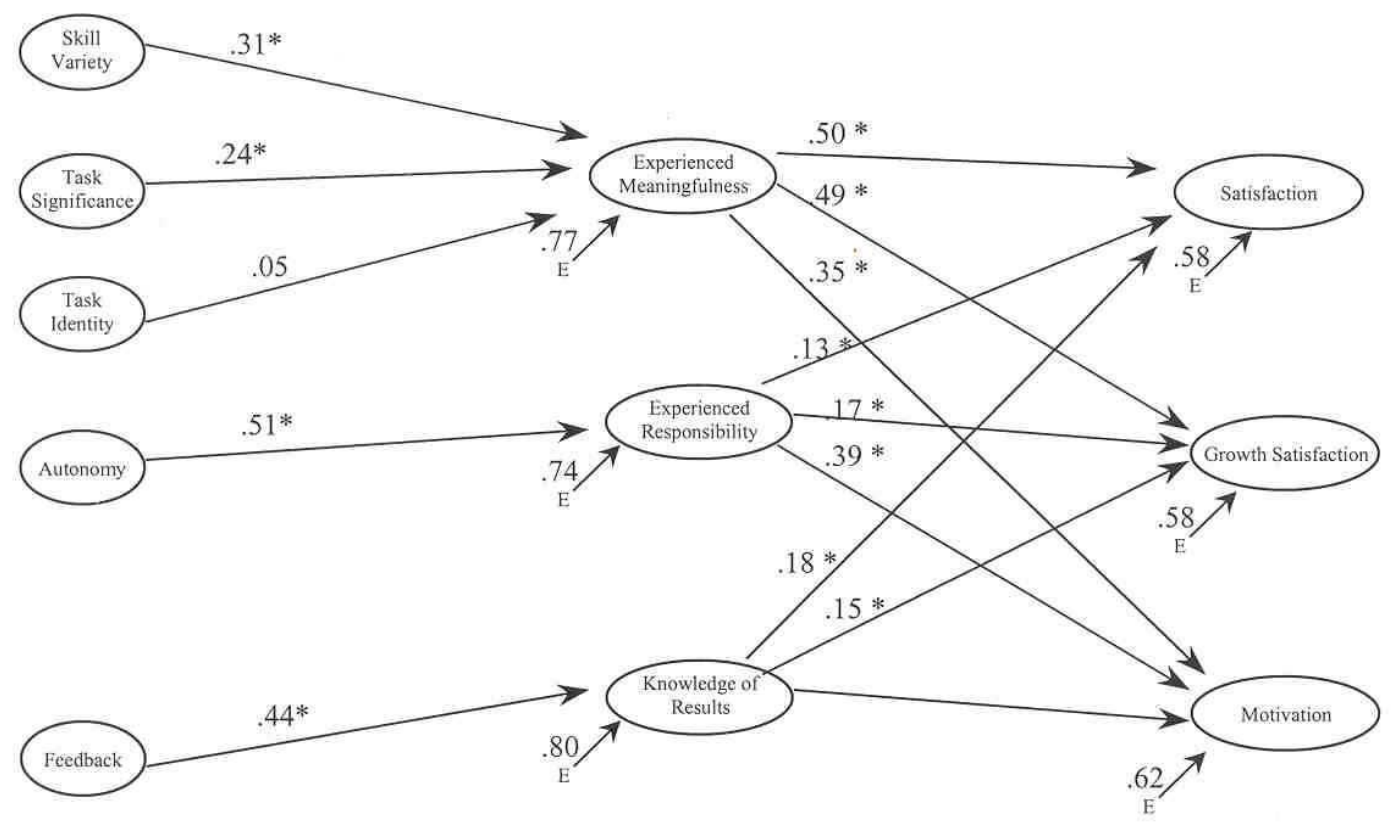


Further, all of the studies that have investigated the JCM (including Behson et al., 2000) have done so using correlational and regression techniques. However, due to the noted problems with using regression analysis to determine the relative strength of prediction among independent variables (Nunnaly \& Bernstein, 1994), regressionbased techniques (including factor analysis and structural equation modeling) do not represent the most appropriate analytic strategy for determining the amount of criterion variance that is uniquely attributable to each of the independent variables. Thus, to date, no research on the motivational approach to job design (and little research in organizational behavior generally) have used analytic strategies specifically constructed to validly test such hypotheses (see Behson, 2005, Budescu 1993, and Johnson, 2004, for details and examples).

Therefore, it remains unclear whether (a) each of the five core job characteristics make a unique contribution to the explained variance in the three critical psychological states, (b) each of the three CPS make a unique contribution to the explained variance in the three most commonly studied important dependent variables (job satisfaction, satisfaction with growth opportunities, and intrinsic motivation), or (c) if each of the five CJCs make a unique contribution to the explained variance in the three dependent variables. In this paper, I use Johnson's (2000) Relative Weight procedure to provide a statistical test of these research questions, using the comprehensive meta-analytic results of Behson, et al. (2000) as my data set.

While I do not offer formal hypotheses for this study, the preponderance of the research on the JCM suggests that:

- Skill variety, task identity and task significance should be the major predictors of experienced meaningfulness

- $\quad$ Autonomy should be the primary predictor of experienced responsibility

- $\quad$ Feedback should be the primary predictor of knowledge of results

- $\quad$ All CPS should be related to the three outcome measures, but with no particular predictions of relative weight

- $\quad$ All CJC should be related to the three outcome measures, with no particular predictions of relative weight. However, the CJC should not be as predictive of outcomes as are the CPS

These predictions are made knowing that, in the past, they have only been tested largely by comparing correlation coefficients or regression-based analyses, which, as will be explained in more detail in the methods section, are prone to bias and, therefore, not the most appropriate analytic strategies for testing such hypotheses. The current study uses Johnson's (2000) relative weights procedure to provide the first test of organizational justice using the most appropriate technique for explaining the unique contribution to $\mathrm{R}^{2}$ among multiple independent variables.

\section{METHOD}

\section{Dataset and Measures}

The Behson, et al. (2000) meta-analysis was chosen for this study because it is the most comprehensive recent quantitative review of the JCM. It includes thirteen independent studies that each contained information regarding the full JCM model and reported correlations between CPS and CJC and/or outcome measures. By comparison, while Friend and Ferris (1987) and Loher et al. (1985) included more studies, they did not contain as many studies that examined the entire JCM. Further, because Behson, et al. (2000) used their meta-analytic results as input into a structural equation model, their results provide an excellent opportunity to compare the results of the relative weight procedure against those derived from less appropriate regression analyses. Finally, every study contained in the meta-analysis used the Job Diagnostic Survey developed by Hackman and Oldham (1975) to measures all variables in the model. As a result, this meta-analysis did not encounter the potential confound of combining various operationalizations into a single metric. Please see the original article for a list of studies used in the meta-analysis, as well as a thorough treatment of their analytic methods. 


\section{Analytic Strategy}

Traditional multiple regression maximizes prediction of a dependent variable by assigning weights to predictors in such a way that the sum of squares attributable to error is minimized (Nunnaly \& Bernstein, 1994). However, multiple regression does a poor job in sorting out the relative importance of different predictors, especially in the presence of multicollinearity (Johnson, 2000). Specifically, regression, including stepwise and hierarchical approaches as well as structural equations models which rely on both factor analytic and regression techniques, will overestimate the importance of the strongest predictors, will underestimate the importance of the less important predictors, and will allow slight differences in inter-predictor correlations to change the pattern of derived regression weights (Budescu, 1993; Johnson, 2000).

In response to the limitations of multiple regression to reliably and accurately determine the relative importance of predictors, a number of measures of relative importance have been introduced. Of these, Budescu's Dominance Analysis (Azen \& Budescu, 2003; Budescu, 1993) and Johnson's Relative Weight Procedure (Johnson, 2000, 2001) are seen as the most valid, as both: (a) contain no logical flaws in their development, (b) are expressed as a proportion of $\mathrm{R}^{2}$ attributable to each independent variable, and (c) consider both direct effects and effects of variables considering the other independent variables in the model (Johnson, 2004).

Dominance analysis allows for a pairwise comparison of all predictors in a proposed model based on each variable's relative contribution to total $\mathrm{R}^{2}$. All possible subsets of the regression model are tested, and each predictor's direct effect (i.e., when considered by itself), total effect (i.e., conditional on all other predictors) and partial effect (i.e., conditional on all possible subsets of predictors) are assessed. These three effects are then averaged together into a "mean usefulness" index. This value then can be used to compare among predictors.

Johnson's relative weight procedure (2000) also corrects for the effects of multicollinearity among predictors and more accurately determines each predictor's unique contributions to the explained variance of the dependent variable. However, as opposed to assessing all possible subsets of the regression model, this procedure regresses the predictor variables onto a set of orthogonal factors, resulting in a set of predictors that no longer exhibit multicollinearity. This technique is analogous to the use of an orthogonal rotation during a factor analysis. Johnson and LeBreton (2004) and Behson $(2002,2005)$ found that this procedure generates results that are nearly identical to those produced through a dominance analysis. This technique is more fully described by Johnson (2000, 2001).

In this study, dominance analysis is not conducted because this technique requires not only a correlation matrix but also means and standard deviations to compute, and the Behson, et al. (2000) meta-analysis estimates all means and standard deviations based on Oldham, Hackman \& Stepina (1979) rather than calculating it from the meta-analytic data (while this was probably a proper decision for their purposes, it limits my choice in analytic technique).

\section{Results}

Table 1 reports the results of the relative weights analysis. Specifically, this table lists the total variance in each dependent variable explained by the three CPS or the five CJC (the total $\mathrm{R}^{2}$ ), and then lists how much of this total $\mathrm{R}^{2}$ can be attributed to each of those constructs. Both the unique $\mathrm{R}^{2}$ for each dimension and the percentage of the total $\mathrm{R}^{2}$ that the unique $\mathrm{R}^{2}$ represents are reported. Thus, looking at the first column in the first set of results, we can see that all five CJC dimensions, taken together, account for $35 \%$ of the total variance in experienced meaningfulness. Further, $7.4 \%$ of the variance in experienced meaningfulness is uniquely explained by autonomy, representing $21 \%$ of total $\mathrm{R}^{2}$ explained by all five CJC dimensions.

In the first set of results in Table 1, we can see that the results are somewhat consistent with Hackman and Oldham's (1976) model, as well as the Behson, et al. (2000) results. According to the model, experienced meaningfulness should be primarily explained by skill variety, task significance and task identity. Skill variety and task significance explain $28 \%$ and $29 \%$ of the explained variance in experienced meaningfulness, but task identity explains far less. All three combine to explain $63 \%$ of the explained variance, which is not proportionately more 
than is explained by the two other CJC. Further, according to the original JCM model, only variety, identity and significance should be significant predictors of experienced meaningfulness; yet, $37 \%$ of the explained variance in meaningfulness is accounted for by the two other CJC. Thus, the results are mixed.

In terms of experienced responsibility, the results show that autonomy explains $29 \%$ of the variance in experienced responsibility. This is single highest result, but is not considerably more than many other CJC. Further, according to the original JCM model, only autonomy should be a significant predictor of experienced meaningfulness; yet, 71\% of the explained variance in responsibility is accounted for by the four other CJC. Again, the results are mixed.

In terms of knowledge of results, feedback does explain by far the largest amount of variance (63\%), which is consistent with the model. Overall, results provide some support for the model and prior findings, but demonstrate that expected relationships may not be as strong or consistent as commonly hypothesized. In particular, this analysis reveals that the five CJC do not exhibit the degree of discriminant validity proposed by Hackman \& Oldham (1976) or Behson, et al. (2000). Thus, the impact of one particular CJC is more difficult to distinguish from the impact of the others. Thus, the five CJC, taken collectively, may be a better predictor of overall reactions than each CJC is in predicting its corresponding CPS.

Table 1. Results of the Relative Weights Analysis for the Job Characteristics Model

\begin{tabular}{|l|c|c|c|c|c|c|}
\hline \multirow{2}{*}{ Skill Variety } & \multicolumn{2}{|c|}{ Experienced Meaningfulness } & Experienced Responsibility & \multicolumn{2}{c|}{ Knowledge of Results } \\
\cline { 2 - 7 } & raw RW & RW as \% & raw RW & RW as \% & raw RW & RW as \% \\
\hline Task Significance & 0.099 & 28 & 0.045 & 18.5 & 0.007 & 2.4 \\
\hline Task Identity & 0.103 & 29.2 & 0.048 & 19.5 & 0.02 & 7.3 \\
\hline Autonomy & 0.019 & 5.3 & 0.032 & 13.2 & 0.041 & 14.9 \\
\hline Feedback & 0.074 & 21 & 0.071 & 28.9 & 0.034 & 12.3 \\
\hline $\mathbf{R}^{\mathbf{2}}$ & 0.057 & 16.4 & 0.049 & 20 & 0.175 & 63.1 \\
\hline
\end{tabular}

\begin{tabular}{|c|c|c|c|c|c|c|}
\hline & \multicolumn{2}{|c|}{ Job Satisfaction } & \multicolumn{2}{|c|}{ Growth Satisfaction } & \multicolumn{2}{|c|}{ Intrinsic Motivation } \\
\hline & raw $\mathbf{R W}$ & RW as \% & raw $\mathbf{R W}$ & RW as \% & raw $\mathbf{R W}$ & RW as \% \\
\hline $\begin{array}{l}\text { Experienced } \\
\text { Meaningfulness }\end{array}$ & 0.268 & 57.6 & 0.265 & 57.1 & 0.063 & 12.6 \\
\hline $\begin{array}{l}\text { Experienced } \\
\text { Responsibility }\end{array}$ & 0.11 & 23.6 & 0.124 & 26.7 & 0.199 & 39.6 \\
\hline Knowledge of Results & 0.087 & 18.8 & 0.075 & 16.2 & 0.24 & 47.8 \\
\hline $\mathbf{R}^{2}$ & 0.465 & & 0.464 & & 0.502 & \\
\hline
\end{tabular}

\begin{tabular}{|c|c|c|c|c|c|c|}
\hline & \multicolumn{2}{|c|}{ Job Satisfaction } & \multicolumn{2}{|c|}{ Growth Satisfaction } & \multicolumn{2}{|c|}{ Intrinsic Motivation } \\
\hline & raw $R W$ & RW as \% & raw $\mathbf{R W}$ & RW as \% & raw RW & RW as \% \\
\hline Skill Variety & 0.051 & 20.3 & 0.117 & 27.6 & 0.054 & 22.1 \\
\hline Task Significance & 0.031 & 12.4 & 0.053 & 12.6 & 0.049 & 19.9 \\
\hline Task Identity & 0.017 & 6.7 & 0.021 & 5 & 0.008 & 3.2 \\
\hline Autonomy & 0.092 & 36.6 & 0.15 & 35.2 & 0.031 & 12.8 \\
\hline Feedback & 0.06 & 24 & 0.084 & 19.7 & 0.103 & 42 \\
\hline $\mathbf{R}^{2}$ & 0.251 & & 0.426 & & 0.246 & \\
\hline
\end{tabular}

In the second set of results, we offered no particular expectation for the relative importance of the three CPS on the outcome variables. Results show that experienced meaningfulness is the most important in predicting job satisfaction and growth satisfaction (accounting for $57.6 \%$ and $57.1 \%$ of explained variance in those outcome variables, respectively). However, meaningfulness plays a much lesser role in explaining variance in intrinsic motivation, which is better explained by the other variables (experienced responsibility explains $39.6 \%$ of explained variance in intrinsic motivation and knowledge of results explains $47.8 \%$ ). 
The third set of results examines the job characteristics model as it is commonly tested- without the CPS included. These results show that autonomy plays a prominent role in explaining job and growth satisfaction, while feedback plays a primary role in explaining variance in intrinsic motivation. Task identity explains little variance in any of the dependent variables studied. As expected, the CJC collectively do not explain as much variance in the outcome variables as the CPS do. Further, similar to the first set of results, this analysis reveals a lack of discriminant validity among CJC. Taken together, these results provide some support for the model and prior findings, but demonstrate that expected relationships may not be as strong or consistent as commonly hypothesized.

\section{Discussion}

Much of the JCM remains robust, and the results of this analysis confirm the importance of such bedrock principles as experienced meaningfulness, autonomy and feedback in explaining reactions to one's work. However, the model suffers from the fact that many of the elements in the model are closely related and the three-stage model can be considered somewhat redundant (for example, are separate measures of feedback and knowledge of results both needed?). The JCM is an important theory because it illuminates a handful of important concepts, and has been built on by researchers and practitioners for decades.

However, its broad applicability can also be seen as a reason for the muddled and sometimes contradictory results found by many researchers, including those of this study. For example, what would be considered high skill variety for a factory worker would probably pale in comparison to what a white-collar employee considers low-tomedium skill variety. The Behson, et al. (2000) meta-analysis combined the results from such varied samples as teachers, engineers, sales professionals, enlisted US Navy troops, and work-study students. While their moderator analyses did not uncover any differences among sample types, it is likely that such combinations of samples led to lowered reliability of measures and more muddled responses. The same could be said for the Fried \& Ferris (1987) and Loher, et al. (1985) meta-analyses.

Further, the JCM's rapid ascendance as the dominant theory in job design research may have had unintended consequences. Because of the respect and deference many had towards the JCM, other models and alternate theories were slow to develop (Parker \& Ohly, 2009). Johns (2010) contends that the field of job design research has been stuck in the past, and has not adapted to changes in the workplace due to overly strict adherence to the JCM, which was proposed 34 years ago, before the advent of major technological advances.

Oldham and Hackman (2010) themselves have written that they never intended the JCM to be the final word on job design research, and they encourage researchers to expand the scope of their inquiries. This is especially true given how the workplace has changed. The JCM does not take into account several now-common forms of work organization and job design, including telecommuting, virtual teams and distributed work groups. The cultures of many workplaces have made a shift from top-down command-and-control approaches to those that emphasize collaboration and employee decision-making. In a more interconnected world, many jobs are now performed with greater interdependence and constant communication with co-workers, customers, and liaisons from a broad network of other companies. Thus, one would expect the influence of the interpersonal situation of one's work to be paramount in shaping one's satisfaction, growth and intrinsic motivation (Grandey \& Diamond, 2010, Morgeson, Dierdorff \& Hmurovic, 2010).

For all of these reasons, job design researchers need to expand the scope of their research beyond the JCM. Karasek's (1979) approach to job design and motivation, which emphasizes one's job demands, as well as the amount of control and the amount of support given to meet those demands, may be particularly well-suited to exploring the modern workplace. This model also explores how stress and well-being influence one's reactions to one's job. In one example of a useful extension of the JCM, Grzywacz and Butler (2005) have examined how autonomy and skill variety influence one's ability to manage work-family conflict. More research extending the reach of job design through alternate models and an expanded set of antecedents/outcomes is needed to better examine the effects of job design in the modern workplace.

Overall, this critique of job design research is not as much a critique of the JCM as it is how others have reacted to this model. JCM is still useful, albeit imperfect. The way in which it has been used as the default "final 
word' in job design research has kept this field from contributing as much as it could have to management research and practice (Oldham \& Hackman, 2010). Only by critically re-analyzing JCM research, do these shortcomings become more apparent, demonstrating the value of such re-analysis.

\section{Study 2- Organizational Justice}

There has been over 35 years of accumulated research into organizational justice. In this literature, several different conceptions of justice have been forwarded, validated, and tested for discriminant validity. In particular, four facets of justice have been identified and explored: distributive justice- based on outcomes (Adams, 1965), procedural justice- based on process (Leventhal, 1980), informational justice- based on data-driven explanations of decisions (Greenberg, 1993) and interactional justice- based on personal treatment (Bies \& Moag, 1986). All four dimensions have been extensively studied; the validity and importance of these justice dimensions have stood the test of time and the peer-review scientific process (see Colquitt, Greenberg \& Zapata-Phelan, 2005 and Greenberg \& Colquitt, 2005 for excellent historical overviews).

These facets have been validated, have been distinguished from each other using factor analytic and other techniques (Ambrose \& Arnaud, 2005; Cropanzano \& Ambrose, 2001), and their relationships with outcome variables (such as satisfaction, commitment, retaliation, and decision acceptance) have been distinguished through regression analyses and structural equations modeling (e.g., Colquitt, 2001). As such, a general consensus has emerged of a four-dimensional- distributive, procedural, interpersonal, and informational- understanding of organizational justice (see Colquitt, 2001). There is little question to the distinctiveness of distributive and procedural justice (Ambrose \& Arnaud, 2005; Cropanzano \& Ambrose, 2001), and procedural from interpersonal justice (Bies, 2005). There is also considerable evidence that, despite some conceptual and measurement overlap, these dimensions of justice are best seen as distinct but inter-related in meaningful ways (Brockner \& Wiesenfeld, 2005). This literature has been summarized by several meta-analyses (Cohen-Charash \& Spector, 2001; Skitka, Winquist \& Hutchinson, 2003), including one which performed regression analyses based on the derived metaanalytic data (Colquitt, Conlan, Wesson, Porter \& Ng, 2001).

While the accumulated literature is generally supportive of the four dimensions of organizational justice, this support is by no means universal. In particular, questions remain regarding the independence of justice dimensions (e.g., Bies, 2005; Sweeney \& McFarlane, 1997) and whether the role of distributive justice had been underestimated (Skitka et al., 2003). What remains most open to question is the marginal utility of different justice dimensions- whether the addition of another justice dimension accounts for additional unique variance in important employee outcome variables (see Cohen-Charash \& Spector, 2001).

Further, due to the noted problems with using regression analysis to determine the relative strength of prediction among independent variables (Nunnaly \& Bernstein, 1994), regression-based techniques (including factor analysis and structural equation modeling) do not represent the most appropriate analytic strategy for determining the amount of criterion variance that is uniquely attributable to each of the independent variables. However, to date, no research on organizational justice (and little research in organizational behavior generally) have used analytic strategies specifically constructed to validly test such hypotheses (see Behson, 2005, Budescu 1993, and Johnson, 2004, for details and examples). Thus, it remains unclear whether each of the four dimensions of organizational justice make a unique contribution to the explained variance of a number of important dependent variables, and if one or more of the dimensions is more important in predicting variance in these dependent variables. In this paper, I use Johnson's (2000) Relative Weight procedure to provide such a statistical test, using the comprehensive metaanalytic results of Colquitt, et al. (2001) as my data set.

There is considerable conceptual and empirical evidence to support the notions that certain dimensions of justice should have larger effects on certain outcomes than other dimensions of justice (Cropanzano, Prehar \& Chen, 2002). For instance, it is generally posited that distributive justice is closely associated with employee reactions tied closely to the decision itself, such as decision acceptance and outcome satisfaction. Similarly, procedural justice is generally seen to be closely associated with employee reactions aimed at the larger decision-making system (Bies, 2005), and often the organization itself (e.g., satisfaction with a reward system, organizational commitment). Interpersonal and informational justice are most often associated with employee reactions focused on the individual 
who makes and explains decisions, often a supervisor (Bies, 2005; Cropanzano, et al., 2002). As summarized by Robbins and Judge (2008), “...distributive justice is most strongly related to satisfaction with outcomes and organizational justice. Procedural justice relates most strongly to job satisfaction, employee trust, withdrawal, job performance, and citizenship behaviors. There is less evidence on interactional justice" (p. 83). This statement is mostly consistent with the aforementioned research. The preponderance of the research on organizational justice suggests the following expectations for the results of this study:

- $\quad$ For outcome measures directed closely at the decision-level, such as outcome satisfaction, distributive justice should be the most important predictor

- For outcome measures directed at the supervisory or job-related level, such as evaluation of supervisor, withdrawal and job satisfaction, interpersonal and informational justice should be the most important predictors

- $\quad$ For outcome measures directed at the system or organizational level, such as organizational commitment and organizational citizenship behaviors, procedural justice should be the most important predictor

These predictions are made knowing that, in the past, they have only been tested largely by comparing correlation coefficients (e.g., Cohen-Charash \& Spector, 2001) or with regression-based analyses (e.g., Colquitt, et al., 2001; which used hierarchical regression and Cropanzano, et al., 2002; which used canonical correlation), which, as will be explained in more detail in the methods section, are prone to bias and, therefore, not the most appropriate analytic strategies for testing such hypotheses. The current study uses Johnson's (2000) relative weights procedure to provide the first test of organizational justice using the most appropriate technique for explaining the unique contribution to $\mathrm{R}^{2}$ among multiple independent variables.

\section{METHODS}

\section{Dataset, Measures and Analytic Strategy}

The Colquitt, et al. (2001) meta-analysis was chosen for this study because it is the most comprehensive recent quantitative review of the organizational justice literature (including 183 published studies over 25 years), was impeccably conducted, and contains full correlation information among all four dimensions of justice as well as a wide array of important consequences of justice. By comparison, the Cohen-Charash \& Spector (2001) and the Skitka, et.al. (2003) meta-analyses do not include enough information to calculate a correlation matrix nor do they include all four dimensions of justice. Further, Colquitt et al. (2001) use their meta-analytic results as input into a series of hierarchical regression models in order to explore a number of research questions. Their results provide an excellent opportunity to compare the results of the relative weight procedure against those derived from less appropriate regression analyses. Please see the original article for a list of studies used in the meta-analysis, as well as a thorough treatment of their analytic methods.

Colquitt et al. (2001) do not provide full information on which operationalizations were included for their constructs. However, given its publication in the Journal of Applied Psychology, it is reasonable to conclude that most of the included studies used commonly-used measures of employee outcomes. This, however, is no means assured, and some studies might have used newly-constructed, non-validated or single-item measures. This lack of information is a potential problem with both the original meta-analysis and, by extension, the present study.

In this study, Johnson's relative weight procedure is applied to the correlation matrices derived from the Colquitt, et al. (2001) meta-analysis. As in the prior study, dominance analysis is not conducted because this technique requires not only a correlation matrix but also means and standard deviations to compute. However, due to the nature of how meta-analytic studies combine the results of multiple studies which may use slightly different measures, this information is not available (it may not have been valid to use it anyway).

\section{RESULTS}

Table 2 reports the results of the relative weights analysis. Specifically, this table lists the total variance in each dependent variable explained by the four dimensions of organizational justice (the total $\mathrm{R}^{2}$ ), and then lists how 
much of this total $\mathrm{R}^{2}$ can be attributed to each of the four dimensions. Both the unique $\mathrm{R}^{2}$ for each dimension and the percentage of the total $R^{2}$ that the unique $R^{2}$ represents are reported. Thus, looking at the first set of results, we can see that all four dimensions, taken together, account for $38 \%$ of the total variance in job satisfaction. Further, $30 \%$ of the variance in job satisfaction is uniquely explained by distributive justice, representing $78 \%$ of total $\mathrm{R}^{2}$ explained by all four dimensions.

As can be seen in Table 2, the results of the relative weights analysis show distributive justice to account for the greatest amount of explained variance in most of the studied dependent variables. Specifically, distributive justice accounts for $77.5 \%$ of the explained variance in outcome satisfaction, $55.7 \%$ of the explained variance in job satisfaction, $72.3 \%$ of the explained variance in organizational commitment, and $61.9 \%$ of the explained variance in withdrawal.

Table 2. Results of the Relative Weights Analysis, Showing the Unique Contribution to $\mathbf{R}^{2}$ of the Four Justice Dimensions on Employee Outcome Variables

\begin{tabular}{|c|c|c|c|c|c|c|}
\hline & \multicolumn{2}{|c|}{ Outcome Satisfaction } & \multicolumn{2}{|c|}{ Job satisfaction } & \multicolumn{2}{|c|}{ Organizational Commitment } \\
\hline & raw $R W$ & RW as \% & raw $R W$ & RW as \% & raw $R W$ & RW as \% \\
\hline Procedural justice & 0.038 & 10 & 0.054 & 15.2 & 0.032 & 11.7 \\
\hline Interpersonal justice & 0.013 & 3.4 & 0.034 & 9.6 & 0.011 & 3.9 \\
\hline Informational justice & 0.035 & 9.1 & 0.069 & 19.5 & 0.033 & 12.1 \\
\hline Distributive justice & 0.297 & 77.5 & 0.196 & 55.7 & 0.195 & 72.3 \\
\hline Total $\mathbf{R}^{2}$ & 0.384 & & 0.352 & & 0.270 & \\
\hline
\end{tabular}

\begin{tabular}{|l|c|c|c|c|c|c|}
\hline & \multicolumn{2}{|c|}{ Citizenship Behaviors } & \multicolumn{2}{c|}{ Withdrawal } & \multicolumn{2}{c|}{ Supervisor Evaluation } \\
\cline { 2 - 7 } & raw RW & RW as \% & raw RW & RW as \% & raw RW & RW as \% \\
\hline Procedural justice & 0.015 & 15.9 & 0.051 & 15.3 & 0.125 & 21.6 \\
\hline Interpersonal justice & 0.043 & 46.8 & 0.040 & 12 & 0.140 & 24.2 \\
\hline Informational justice & 0.028 & 30.5 & 0.036 & 10.9 & 0.158 & 27.3 \\
\hline Distributive justice & 0.006 & 6.8 & 0.206 & $\mathbf{6 1 . 9}$ & 0.155 & 26.8 \\
\hline Total $\mathbf{R}^{\mathbf{2}}$ & 0.093 & & 0.333 & & 0.577 & \\
\hline
\end{tabular}

Note: Numbers in boldface represent a percentage of explained variance that exceeds the next highest percentage by at least 30 percentage points.

Two outcome measures were not chiefly explained by distributive justice. Interpersonal justice accounted for $46.8 \%$ of the explained variance in organizational citizenship behaviors, while distributive justice accounted for only $6.8 \%$. Further, no single justice dimension emerged as more important in explaining supervisor evaluation (all dimensions explained from $21 \%$ to $27 \%$ ). The latter result is most likely due to the very general nature of the dependent variable, which combined evaluations of one's real-life work supervisor (with whom the respondent probably has a long-term complex relationship) in organizational field studies with evaluations of an experimenter (with whom the respondent probably had one short-term interaction) in laboratory studies.

Although I did not proffer formal hypotheses in this study, these results defy expectations. As stated earlier, there is general consensus that distributive justice should be most important in explaining variables such as outcome satisfaction, which are related closely to the decision or decision-maker. However, it is also expected that procedural justice would be most predictive of outcome variances directed at the larger organization or system, such as organizational commitment or organizational citizenship behaviors, and that interpersonal and informational justice would be most predictive of outcome variances directed at the supervisory level. By and large, these predictions were not supported.

In sum, of the four major dimensions of justice (after accounting for multicollinearity using the best suited analytic technique to do so), distributive justice is determined to be by far the most important predictor of outcome satisfaction, job satisfaction, organizational commitment and withdrawal. While this was expected for outcome satisfaction, these results defy expectations that procedural justice would be the most important for predicting organizational commitment and withdrawal, and that interpersonal and informational justice would be primary for job and supervisor satisfaction. Further, interpersonal justice, not procedural justice, was the primary predictor of organizational citizenship behaviors. 


\section{DISCUSSION}

This study represents a meaningful contribution to our understanding of organizational justice. These results provide evidence that the importance of distributive justice should not be overlooked as we increasingly study procedural, interpersonal and informational justice. Specifically, distributive justice accounts for the largest shares of unique explained variance in a wide range of employee outcomes. Thus, in the inter-relationship of distributive and procedural justice, distributive justice may be seen as the senior partner.

These results call into question the marginal utility of process-based dimensions of justice in predicting many important employee reactions to organizational and managerial decisions. The primacy of distributive justice is inconsistent with much of the current work on justice, which has developed and validated a more fine-grained understanding of justice and its dimensions (see Ambrose \& Arnaud, 2005; Bies, 2005; and Colquitt, 2001).

However, the finding of the primacy of distributive justice is not unprecedented. Some earlier work on interpersonal justice, such as Sweeney \& McFarlane (1997) found high levels of intercorrelation between distributive and procedural justice, calling into question the marginal utility of procedural justice. Compounding the problem is Ambrose and Arnaud's (2005) observation that many of the studies focused on the marginal utility of justice dimensions had not properly controlled for distributive justice before examining process. However, the use of relative weights allows one to decouple the inter-relations of the various dimensions of justice, addressing their very legitimate concern.

The current findings are also consistent with research relating to decision biases and selective perception, including Lind's (2001) fairness heuristic theory that posits that individuals make a judgment to the overall fairness of a decision, and then use subsequent information to corroborate their initial judgment. Thus, individuals may decide first on the favorability of an outcome and then, based on their favorable or unfavorable appraisal, construct a narrative regarding the procedural or interactional fairness of the decision. For example, someone receiving a positive outcome may also judge the process by which the decision was made as more fair than it really was and someone who received a just negative outcome is likely to question the process. More recently, Ambrose and Schminke (2009) built on this idea by positing that overall perceptions of justice mediate the relationship between specific justice facets and outcomes. That is, individuals do not initially differentiate among justice dimensions; rather they make an overall judgment regarding fairness before considering the impact of specific justice dimensions. It is possible that distributive justice may play a particularly large role in determining overall justice perceptions.

While I would not advocate managers to make decisions utilizing anything less than fair process, respectful treatment and transparent information (see Cropanzano, Bowen \& Gilliland, 2007 for an excellent treatment of practical advice based on organizational justice research), these measures may represent less comfort to those receiving negative outcomes than commonly determined by researchers; the perceived accuracy of outcome-related decisions is of paramount importance in shaping employee reactions. The importance of distributive justice is sometimes lost as the accumulated research has instead highlighted the more psychologically interesting procedural, interactional and informational justice dimensions. This has skewed our understanding of organizational justice.

This study also has methodological implications. In particular, these results demonstrate how the predictions we make about marginal utility and unique contribution to $\mathrm{R}^{2}$ based on regression can be misleading. For example, Colquitt, et al's (2001) hierarchical regression analyses based on their meta-analytic data are generally supportive of the marginal utility of the more recently-developed dimensions of justice over the effects of distributive justice alone. However, multicollinearity was not fully accounted for in these calculations, leading to a number of potentially biased results (Nunnaly \& Bernstein, 1994).

\section{General Discussion}

This study provides a methodological contribution to the field of organizational behavior as it is one of only a handful of studies in this field (see Behson, 2002, 2005, and Johnson \& LeBreton, 2004) to revisit prior research using a recently developed and superior analytic technique for determining the unique contribution of independent 
variables to explained variance of a dependent variable. Such critical re-analyses are an important but all too infrequently performed part of the scientific process, especially as they relate to research streams in the "consolidation and accommodation" stage of development (Reichers \& Schneider, 1990).

The fact that the results of these studies are inconsistent with past findings is most likely attributable to the use of an analytic technique best suited for determining the unique contributions of various independent variables on the explained variance of outcomes. The relative weights procedure corrects for multicollinearity and avoids many of the biases associated with regression-based techniques.

However, it is also possible that there were flaws both in the present study and in the Behson et al. (2000) and Colquitt et al. (2001) meta-analyses from which the data are taken. For example, in the Colquitt et al. (2001) meta-analysis, we do not have detailed information about how the various operationalizations of justice and outcome measures were included or excluded, and how they were combined. It is probable that the muddled results regarding evaluation of supervisor reactions is due to combining the different types of supervisor relationships found between laboratory and field studies. Further, while these meta-analyses represent the most recent comprehensive reviews in their fields, they are both about a decade old, and necessarily exclude more recent literature.

Another common limitation of both studies is that there is no easily calculable method for determining statistically significant differences among relative weights (Johnson, 2001). I have attempted to be conservative in interpreting these findings and encourage the reader to be similarly conservative so that we do not overstate small differences in relative weight.

In conclusion, this study will hopefully encourage more researchers to utilize relative weights and other analytic techniques that are most appropriate for testing hypotheses of comparative and marginal utility. Multiple regression maximizes the prediction of a dependent variable using a set of data, but is not nearly as useful is determining the differential effects of each of the included independent variables. It is recommended that researchers who are interested in investigating the relative importance (i.e., contribution to explained variance) of predictors utilize the most appropriate methods to do so. Dominance (Budescu, 1993) and relative weights (Johnson, 2000) are two appropriate choices to suit this purpose. Clearly, there are many areas of organizational research in which the relative importance of predictors would be extremely interesting (Johnson, 2001). For example, a measure of relative importance would be appropriate if one is comparing the predictive validities of various employment selection tests and criteria, making decisions for reducing the number of items in a scale, or comparing the contributions of various proposed antecedents to employee turnover.

\section{AUTHOR INFORMATION}

Scott J. Behson is an Associate Professor of Management at the Silberman College of Business of Fairleigh Dickinson University, New Jersey, USA. He teaches a variety of management, organizational behavior and human resource management courses and conducts research into work stress, work-family balance, organizational justice, and high-involvement work practices. In addition to occasional consulting work, Dr. Behson has taught as a visiting professor at the International University of Monaco and La Universidad del Salvador (Buenos Aires). He has won numerous teaching and research awards, including a best paper award for an earlier version of this article at the 2010 EABR conference.

\section{REFERENCES}

1. Adams J.S. (1965). Inequity in social exchange. In L. Berkowitz (Ed.), Advances in experimental social psychology (pp. 267-299). New York: Academic Press.

2. Ambrose, M. \& Arnaud (2005). Are procedural and distributive justice conceptually distinct? In J. Greenberg \& J. A. Colquitt (Eds.), The handbook of organizational justice (pp. 59-84). Mahwah, NJ: Erlbaum.

3. Ambrose, M. \& Schminke, M. (2009). The role of overall justice judgments in organizational justice research: A test of mediation. Journal of Applied Psychology, 94, 491-500. 
4. $\quad$ Azen, R. \& Budescu, D.V. (2003). The dominance analysis approach for comparing predictors in multiple regression. Psychological Methods, 8, 129-148.

5. Behson, S.J. (2002). Which dominates? The relative importance of work-family organizational support and general organizational context on employee outcomes. Journal of Vocational Behavior, 61, 53-71.

6. Behson, S.J. (2005). The Relative Contribution of Formal and Informal Organizational Work-Family Support. Journal of Vocational Behavior, 66, 487-500.

7. Behson, S.J., Eddy, E.R. \& Lorenzet, S.J. (2000). The Importance of the Critical Psychological States in the Job Characteristics Model: A Meta-Analytic and Structural Equations Modeling Examination. Current Research in Social Psychology, 5 (9), 170-189.

8. Bies, J.R.\& Moag, J.F. (1986). Interactional justice: Communication criteria of fairness. In R.J. Lewicki, B.H. Sheppard \& M.H. Bazerman (Eds.), Research on negotiations in organizations (pp. 43-55). Greenwich, CT: JAI Press.

9. Bies, R.J. (2005). Are procedural and interactional justice conceptually distinct? In J. Greenberg \& J. A. Colquitt (Eds.), The handbook of organizational justice (pp. 88-112). Mahwah, NJ: Erlbaum.

10. Boonzaier, B \& Ficker, B.R. (2001). A review of research on the job characteristics model and the attendant job diagnostic survey. South African Journal of Business Management 32:11, 11-34.

11. Budescu, D.V. (1993). Dominance analysis: A new approach to the problem of relative importance of predictors in multiple regression. Psychological Bulletin, 114, 542-551.

12. Cohen-Charash, Y. \& Spector, P.E. (2001). The role of justice in organizations: A meta-analysis. Organizational Behavior and Human Decision Processes, 86, 278-321.

13. Colquitt, J. A., Greenberg, J., \& Zapata-Phelan, C. P. (2005). What is organizational justice? A historical overview. In J. Greenberg \& J. A. Colquitt (Eds.), The handbook of organizational

14. Colquitt, J.A. (2001). On the dimensionality of organizational justice: A construct validation of a measure. Journal of Applied Psychology, 86, 386-400.

15. Colquitt, J.A., Conlon, D.E., Wesson, M.J., Porter, C.O. \& Ng, K.Y. (2001). Justice at the millennium: A meta-analytic review of 25 years of organizational justice research. Journal of Applied Psychology, 86, 425-445.

16. Cropanzano, R., \& Ambrose, M. L. (2001). Procedural and distributive justice are more similar than you think: A monistic perspective and a research agenda. In J. Greenberg \& R. Cropanzano (Eds.), Advances in organizational justice (pp. 119-151). Stanford, CA: Stanford University Press.

17. Cropanzano, R., Bowen, D. E., \& Gilliland, S. W. (2007). The management of organizational justice. Academy of Management Perspectives, 21, 34-48.

18. Cropanzano, R., Prehar, C.A. \& Chen, P.Y. (2002). Using social exchange theory to distinguish procedural from interactional justice. Group and Organization Management, 27, 324-351.

19. Fox, S. \& Feldman, G. (1988). Attention state and critical psychological states as mediators between job dimensions and job outcomes. Human Relations, 41, 229-245.

20. Fried, Y. \& Ferris, G.R. (1987). The validity of the job characteristics model: A review and meta-analysis. Personnel Psychology, 40, 287-322.

21. Grandey, A.A. \& Diamond, J.A. (2010). Interactions with the public: Bridging job design and emotional labor perspectives. Journal of Organizational Behavior, 31, 338-350.

22. Greenberg, J. (1987). A taxonomy of organizational justice theories. Academy of Management Review, 12, 9-22.

23. Greenberg, J. (1990). Organizational justice - Yesterday, today and tomorrow. Journal of Management, $16,399-432$.

24. Greenberg, J. (1993). The social side of fairness: interpersonal and informational classes of organizational justice. In R. Cropanzano (Ed.), Justice in the work place: approaching fairness in human resource management (79-103). Hillsdale, NJ: Erlbaum.

25. Greenberg, J., \& Colquitt, J. A. (2005). The handbook of organizational justice. Mahwah, NJ: Erlbaum.

26. Grzywacz, J.G \& Butler, A.B. (2005). The impact of job characteristics on work-to-family facilitation: Testing a theory and distinguishing a construct. Journal of Occupational Health Psychology, 10(2), 97-109

27. Hackman J.R. \& Oldham, G.R. (1976). Motivation through the design of work: Test of a theory. Organizational Behavior and Human Performance, 16, 250-279.

28. Hackman J.R. \& Oldham, G.R. (1980). Work redesign. Reading, MA: Addison-Wesley Publishing Company Inc. 
29. Hackman J.R. \& Oldham, G.R. (1975). Development of the job diagnostic survey. Journal of Applied Psychology, 60, 159-170.

30. Hogan E.L. \& Martell, D.A. (1987). A confirmatory structural equations analysis of the job characteristics model. Organizational Behavior and Human Decision Processes, 39, 242-263.

31. Johns, G. (2010). Some unintended consequences of job design. Journal of Organizational Behavior, 31, 361-369.

32. Johnson, J.W. (2000). A heuristic method for estimating the relative weight of predictor variables in multiple regression. Multivariate Behavioral Research, 35, 1-19.

33. Johnson, J.W. \& LeBreton, J.M. (2004). History and use of relative importance indices in organizational research. Organizational Research Methods, 7, 238-257.

34. Johnson, J.W. (2001). Determining the relative importance of predictors in multiple regression: Practical applications of relative weights. In Columbus, Frank (Ed). Advances in Psychology Research, Vol. V. Huntington, NY: Nova Science Publishers, Inc. pp. 231-251.

35. Karasek, R. (1979). Job demands, job decision latitude and mental strain: Implications for job redesign. Administrative Science Quarterly, 24, 285-306.

36. Leventhal G.S. (1980). What should be done with equity theory? New approaches to the study of fairness in social relationships. In K. Gergen, M. Greenberg \& R. Willis (Eds.), Social exchange: Advances in theory and research (pp. 27-55). New York: Plenum.

37. Lind, E. A. (2001). Fairness heuristic theory: Justice judgments as pivotal cognitions in organizational relations. In J. Greenberg \& R. Cropanzano (Eds.), Advances in organizational justice (pp. 56-88). Stanford, CA: Stanford University Press.

38. Loher, B.T., Noe, R.A., Moeller, N.L. \& Fitzgerald, M.P. (1985). A meta-analysis of the relation of job characteristics and job satisfaction. Journal of Applied Psychology, 70, 280-289.

39. Morgeson, F.P., Dierdorff, E.C. \& Hmurovic, J.L. (2010). Work design in situ: Understanding the role of occupational and organizational context. Journal of Organizational Behavior, 31, 351-360.

40. Nunnaly J.C. \& Bernstein, I.H. (1994). Psychometric theory. New York, NY: McGraw-Hill.

41. Oldham, G.R. \& Hackman, J.R. (2010). Not what it was and not what it will be: The future of job design research. Journal of Organizational Behavior, 31, 463-479.

42. Oldham, G.R., Hackman, J.R. \& Stepina, L.P. (1979). Norms for the Job Diagnostic Survey. JSAS Catalog of Selected Documents in Psychology (Ms. No. 1819), 9, 14.

43. Parker, S.K. \& Ohly, S. (2009). Extending the reach of job design theory: Going beyond the job characteristics model. In A. Wilkinson, M. Bacon, T. Redman \& S. Snell (Eds.) The sage handbook of human resource management. (pp. 269-285). Thousand Oaks, CA: Sage.

44. Reichers, A.E. \& Schneider, B. (1990). Climate and culture: Life cycles of constructs. In B. Schneider (Ed.) Organizational climate and culture. (pp. 5-39). San Francisco: Jossey-Bass.

45. Renn, R.W. \& Vandenberg, R.J. (1995). The critical psychological states: An underrepresented component in job characteristics model research. Journal of Management, 21, 279-303.

46. Roberts, K.H. \& Glick, W. (19810). The job characteristics approach to task design: A critical review. Journal of Applied Psychology, 66, 193-217.

47. Salancik, G.R. \& Pfeffer, J. (1978). A social information processing approach to job attitudes and task design. Administrative Science Quarterly, 23, 224-253.

48. Skitka, L.J., Winquist, J. \& Hutchinson, S. (2003). Are outcome fairness and outcome favorability distinguishable psychological constructs? A meta-analytic review. Social Justice Research, 16, 309-341.

49. Sweeney P.D. \& McFarlane D.B. (1997). Process and outcome: Gender differences in the assessment of justice. Journal of Organizational Behavior, 18 83-98.

50. Taber, T.D. \& Taylor, E. (1990). A review and evaluation of the psychometric properties of the job diagnostic survey. Personnel Psychology, 43, 467-500. 
NOTES 